\title{
ANÁLISE TERRITORIAL NO ESPAÇO URBANO DE TERESINA-PI: DINÂMICAS ESPACIAIS EM TERRITÓRIOS DA ÁREA CENTRAL
}

\author{
Lineu Aparecido Paz e Silva ${ }^{1}$ \\ David José da Silva Carvalho
}

\begin{abstract}
Resumo
O processo de ocupação do espaço caracteriza-se pela demarcação de determinados territórios por grupos sociais e agentes econômicos. Esta pesquisa, que teve como foco a zona urbana de Teresina-PI, apresenta como objetivo, analisar determinadas formas de territorialidade, que ocorre neste município. Nesta pesquisa, foram realizados estudos bibliográficos e pesquisa de campo. Diante do estudo realizado, verificou-se que a territorialidade é um fenômeno que se constrói no dia a dia das pessoas confrontando o conhecimento do local habitado e experiência anteriores. Neste trabalho, ficou observado a existência da ocupação de grupos sociais e agentes econômicos nas devidas áreas citadas para estudo. Diante da análise realizada, pode-se afirmar que, determinados tipos de territórios, resulta das relações sociais entre indivíduos, grupos sociais ou agentes econômicos em seu meio de referência.
\end{abstract}

Palavras-chaves: Espaço urbano; territorialidade; grupos sociais; agentes econômicos; região central de Teresina.

\section{TERRITORIAL ANALYSIS IN URBAN SPACE TERESINA-PI: SPATIAL DYNAMICS IN TERRITORIES OF CENTRAL AREA SUMMARY}

\begin{abstract}
The space occupation process characterized by the demarcation of certain areas for social and economic agents groups. This research, which focused on the urban area of Teresina-PI, has as objective to analyze certain forms of territoriality, which takes place in this city. In this research were conducted bibliographic studies and field research. Before the study, it was found that territoriality is a phenomenon that is built on a daily basis of people confronting the knowledge of the inhabited place and previous experience. In this work, it was observed the existence of the occupation of social groups and economic agents in appropriate areas cited for study. In front of the analysis, it can be said that certain types of territories, results of social relationships between individuals, social groups or economic agents in their reference.
\end{abstract}

Key-words: Urban space; territoriality; social groups; economic agents; central Teresina.

\footnotetext{
${ }^{1}$ Licenciado e Mestre em Geografia pela Universidade Federal do Piauí (UFPI). Doutorando em Geografia pela Universidade de Brasília (UnB). Atua como Professor da Educação Básica da Prefeitura Municipal de Alto Longa-PI e Professor Temporário/PARFOR da Universidade Estadual do Piauí (UESPI).

Email: lineuprofgeo@hotmail.com

${ }^{2}$ Licenciado em Geografia pela Universidade Estadual do Piauí (UESPI) e Mestre em Geografia pela Universidade Federal do Piauí (UFPI). Email: david.carvalho87@ hotmail.com
}

Sociedade e Território - Natal. Vol. 28, N. 1, p. 108-121. Jan./Jun. de 2016 


\section{ANÁLISIS TERRITORIAL EN ESPACIO URBANO TERESINA-PI: DINÁMICA ESPACIAL EN LAS TIERRAS DE CENTRAL}

\section{Resumen}

El proceso de ocupación de espacio que se caracteriza por la demarcación de ciertas áreas para grupos de agentes sociales y económicos. Esta investigación, que se centró en el área urbana de Teresina-PI, tiene como objetivo analizar ciertas formas de territorialidad, que tiene lugar en esta ciudad. En esta investigación se llevaron a cabo los estudios bibliográficos y de investigación de campo. Antes del estudio, se encontró que la territorialidad es un fenómeno que se construye sobre una base diaria de la gente que se enfrenta el conocimiento del lugar habitado y la experiencia previa. En este trabajo, se observó la existencia de la ocupación de los grupos sociales y agentes económicos en las zonas apropiadas para el estudio citado. Delante del análisis, se puede decir que ciertos tipos de territorios, los resultados de las relaciones sociales entre los individuos, grupos sociales o los agentes económicos en su referencia.

Palabras-clave: Espacio urbano, la territorialidad, los grupos sociales, los agentes económicos, el centro de Teresina.

\section{INTRODUÇÃO}

A territorialidade no espaço urbano caracteriza-se, por ser um fenômeno que é constantemente observado nas áreas centrais das grandes cidades. Através do processo de ocupação do espaço geográfico, vai ocorrer a demarcação de determinados territórios por grupos sociais e agentes econômicos (cada elemento ocupando o certo lugar de acordo com os seus objetivos). Nesta conjuntura vai haver a introdução de certos tipos de cultura nos locais a serem ocupados, resultando na formação de diferentes formas de territorialidades, em virtude de o espaço possuir um caráter dinâmico acaba sofrendo transformações qualitativas e quantitativas.

A partir da dinâmica espacial, ocorre no território, novas e velhas territorialidades, produto este, característico da ação de grupos sociais e agentes econômicos que interferem diretamente na ocupação do território. A territorialidade é um fenômeno que se constroi no dia a dia, das pessoas, confrontando seu conhecimento e experiências anteriores, para delimitar e caracterizar o seu território ocupado.

O processo de apropriação do espaço ocorre de diferentes formas, apresentando diversas maneiras de ocupação territorial por grupos sociais ou agentes econômicos. A área central da cidade de Teresina é apenas uma das diversas áreas do Brasil e do mundo onde se 
observa o fenômeno de territorialidade. No caso brasileiro, este fenômeno é constantemente observado nas áreas centrais dos grandes centros urbanos, como é o caso do Pelourinho em Salvador (BA), da praia de Boa Viagem em Recife (PE), da Cracolândia em São Paulo (SP) e a praia de Copacabana no Rio de Janeiro (RJ). Todos estes casos representam diferentes formas de territorialidade, em razão da diversidade étnica e cultural existente em nosso país, e também em razão da existência de diferentes maneiras de o ser humano ocupar o espaço geográfico nas diferentes regiões do Brasil.

O centro da cidade de Teresina apresenta como característica marcante a ocupação devida e indevida de grupos sociais e agentes econômicos em seu espaço no qual se desenvolve em razão das contradições sociais. Pois neste aspecto a territorialidade é resultado dessas contradições, pois quando um morador de rua pede esmola em frente uma casa bancaria e são observados dois tipos de territorialidade, uma é a do morador de rua, que utiliza este determinado território para conseguir ajuda financeira, já a outra territorialidade é a do banco, e diz respeito a utilização deste território para a prestação de serviços.

Esta pesquisa apresentou o interesse em analisar a territorialidade na área central e Teresina, em virtude disso, este estudo foi norteado pela seguinte problemática: quais os fatores que contribuem para a formação da territorialidade na área entral, e também, se a ocupação de grupos sociais e agentes econômicos gera conflitos para a disputa de determinados territórios na área central deste referido espaço, sendo assim, surgiu-nos a idéia de desenvolver este trabalho com a finalidade de investigar os fatores que contribuem para a formação das diferentes formas de territorialidades existentes nos locais pesquisados.

Para responder a problemática levantada, foi determinado como objetivo geral o de analisar o processo de territorialidade no espaço urbano levando-se em consideração significado e a importância deste fenômeno para a região central de Teresina. Como objetivos específicos identificar determinadas formas de territorialidade que ocorrem na área entral da cidade de Teresina, diagnosticar as causas que resultam na ocorrência da territorialidade no centro desta cidade e investigar a importância social e econômica da rua Simplício Mendes, av. Maranhão e praça Saraiva para este município de pesquisado.

O universo desta pesquisa foi à área central de Teresina, em razão de ser uma área frequentada por expressiva parcela da população deste município, já a amostra foram determinados grupos sociais e agentes econômicos que ocupam territórios da avenida Maranhão, rua Simplício Mendes e praça Saraiva, onde que, foram aplicados questionários e 
entrevistas para os diferentes tipos de sujeitos pesquisados que ocupam a área em estudo. Os sujeitos desta pesquisa entrevistados foram os moradores de rua, os lavadores de carros, os ambulantes, os pedestres e os lojistas.

O trabalho de pesquisa ocorreu em dois momentos: o primeiro foi a pesquisa bibliográfica que constituiu na base teórica para a fundamentação deste trabalho e no segundo momento, fez-se, a pesquisa de campo, onde que, se utilizou de questionários e entrevistas para a coleta de dados.

Os métodos utilizados no decorrer da pesquisa foram o levantamento bibliográfico e a pesquisa de campo, onde que, se utilizou os seguintes instrumentos de pesquisa: o levantamento de dados que ocorreu a através da aplicação de questionários, e realização de entrevistas, que objetivou a coleta de dados que permitiram analisar as condições em ocorre o fenômeno da territorialidade nestas ruas e seus respectivos resultados para a região central. $\mathrm{O}$ levantamento percentual dos dados coletados possibilitou a disposição das informações adquiridas em tabelas e gráficos.

De acordo com a pesquisa realizada, ficou observado a contribuição dos lojistas, vendedores ambulantes e lavadores de carros para o desenvolvimento econômico da área central de Teresina, elementos estes que possuem um significado cultural que caracteriza a identidade desta área da cidade tendo como principal fator resultante destas territorialidades a localização além da necessidade que estes agentes têm para ocupar estes territórios.

\section{O TERRITÓRIO E A TERRITORIALIDADE: ASPECTOS GERAIS}

Assim como o espaço, o território também representa um dos conceitos chave da geografia, sendo definido, segundo Rafesttin (1993), fundamentalmente como um espaço caracterizado e delimitado por e a partir de relações de poder. Para se compreender um território é preciso entender quem domina ou influencia quem e como faz. A sua localização depende da posição que os atores em processo de ação interativa ocupam, em diferentes momentos, nas redes de relações sociais. Segundo Souza (1995) este só existe em razão de atores sociais que se movimentam no tempo e no espaço, configurando acumulações e fluxos.

Souza (1995, p.81) diz que: “A palavra território normalmente evoca o 'território nacional' e fez pensar no estado-gestor por excelência do território nacional, em grandes espaços, em sentimentos patrióticos, em governo, em dominação, etc. Santos (1999), por sua vez define o território como um todo que se torna um dado da harmonia forçada entre lugares 
e agentes nele instalados em função de uma inteligência maior, situada nos centros motores da informação. Enquanto que Mesquita (1995) define o território a partir da projeção que os atores fazem de sua identidade.

O território é mais que uma base física para relações entre indivíduos, empresas e instituições, e possui um tecido social e uma organização complexa. Reforçando esta afirmação Lima (2007, p.160) afirma: “um território (espaço apropriado por diferentes grupos) representa na verdade, uma trama de relações com raízes históricas, configurações políticas e identidades com papel ainda pouco conhecido no próprio desenvolvimento econômico".

Território pode também ser configurado nacionalmente e tendo como o Estado o grande administrador. Apesar de que, ele não precisa e nem deve ser delimitado a essa escala, ou associado com a figura do Estado. Territórios existem e são realizados nas mais diversas escalas.

Territórios podem ter um caráter permanente, mas também podem ter uma existência periódica cíclica ou flexível. Nesse sentido, Rafesttin (1993) ressalta que o ator, ao se apropriar de um espaço, concreta ou abstratamente (ainda que pela representação), territorializa o espaço. Sendo assim, o território é um espaço onde se projetou trabalho, energia e informação.

O território pode estar sujeito a normas e leis, que de certa forma, vão caracterizar a sua área. Já os espaços urbanos estão diretamente ligados a normas ou leis, que tanto podem ser impostos pelo governo, como pelos habitantes que vivem em determinados territórios. No que diz respeito à territorialidade, esta se constitui como a projeção de nossa identidade sobre o território, ou seja, é um fenômeno que acontece dentro de um determinado território caracterizando a dinâmica da espacialidade.

Novas e velhas territorialidades se agregam, reproduzindo o espaço, assim transformam o agente social ou econômico em um ator na reprodução do espaço. Vivemos em um mundo em que as grandes cidades ou as metrópoles modernas, tanto do primeiro, como do terceiro "mundo", com toda a sua complexidade e dinamicidade apresentam, exemplos interessantes e variados de "territorialidades flexíveis", como por exemplo, os territórios da prostituição feminina ou masculina (garotas de programa, homossexuais etc.). De acordo com Souza (1995, p 44) a territorialidade flexível é caracterizada por: 
Uma superposição de diversos territórios com formas variadas e limites nãocoincidentes, representando territórios de identidade, característico da ação de grupos sociais e agentes econômicos, onde que, podem existir contradições entre as diversas territorialidades, por conta dos atritos e contradições existentes entre os respectivos poderes.

Esses territórios comumente encontrados em "espaços deteriorados", são apropriados pelo respectivo grupo apenas a noite. Durante o dia, as ruas são tomadas por outro tipo de paisagem humana, típico do movimento diurno com pessoas trabalhando ou fazendo compras em estabelecimentos comerciais, pequenas lojas ou bares, além de moradores das imediações. O caráter deste tipo de territorialidade é considerado como cíclico, pois há uma alternância habitual dos usos diurno e noturno do mesmo espaço.

Seja em países desenvolvidos ou em países subdesenvolvidos, a territorialidade ocorre por causa do processo de acentuação da segregação socioespacial gerada por novas lógicas de produção do espaço urbano, o que inclui seu consumo e apropriação, como afirma Sposito (1998).

Em virtude da ocorrência de diversas formas de territorialidades nos locais citados acima, esta pesquisa visa analisar e esclarecer o porquê de a área central de Teresina apresentar este tipo de ocupação territorial, levando-se em consideração os elementos favorecem para a formação da territorialidade e os fenômenos ocorridos na avenida Maranhão, rua Simplício Mendes e Praça Saraiva, com as suas respectivas conseqüências para essa área da cidade.

\section{ANÁLISE TERRITORIAL E REFLEXOS DA DINÂMICA ESPACIAL DA ÁREA CENTRAL DE TERESINA}

$\mathrm{Na}$ área central de Teresina são vários os exemplos de territorialidade. Este trabalho destacou cinco formas de ocupação territorial que são: a dos lojistas, a dos moradores de rua, a dos lavadores de carro, a dos vendedores ambulantes e a dos pedestres. Todos estes elementos convivem paralelamente em determinados territórios no centro desta cidade, possuindo uma intensa interligação na ocupação do espaço. Cada um destes representa uma forma de territorialidade, que como resultado, gera consequências econômicas e sociais para a dinâmica econômica dessa área da cidade.

A análise que se segue, ocorreu a partir da aplicação de questionários e registro fotográfico, tendo por finalidade diagnosticar as causas e os principais elementos que 
resultam em específicos tipos de territorialidades. Através da coleta de dados, foram analisadas as condições sob quais ocorre o fenômeno da territorialidade nestas ruas e seus respectivos resultados para a região central de Teresina.

Para representar o universo da pesquisa foram aplicados questionários para duzentas pessoas, que representaram os sujeitos pesquisados, estabeleceu-se com amostra 90,4\% dos lojistas situados na praça Saraiva, os quais serão referidos nesta pesquisa como amostra A; 95,7\% dos moradores de rua situados nas imediações deste mesmo local, os quais serão referidos como amostra B; 92,6\% dos lavadores de carro que desenvolvem suas atividades no perímetro compreendido entre o centro administrativo e as imediações da ponte João Luis Ferreira, aos quais se fará referência como amostra C; 47,08\% dos vendedores ambulantes cadastrados em sua devida associação, serão referenciados como amostra D; e 50 pedestres que costumam frequentar o perímetro calçadão da rua Simplício Mendes, a serão referenciados como amostra $\mathrm{E}$.

A área delimitada para a pesquisa foi, a avenida Maranhão a rua Simplício Mendes e a praça Saraiva onde foi realizada a análise da ocupação de grupos sociais e agentes econômicos no território destas áreas a serem pesquisadas. Para diagnosticar a problemática sobre os fatores que contribuem para o processo de territorialidade no espaço urbano do centro de Teresina, além dos estudos teóricos, foi realizado o estudo da realidade acerca do território da área do objeto de estudo, através da pesquisa de campo. O levantamento percentual dos dados coletados possibilitou a disposição das informações adquiridas em tabelas e gráficos.

Em relação ao tempo de utilização do território ocupado na área central do espaço urbano de Teresina, observa-se, que a territorialidade neste local é um fenômeno resultante da própria ocupação histórica da cidade, com áreas tradicionais de ocupação territorial, como é o caso dos lojistas (amostra A) que, de certa forma estão ocupando o espaço da área central (em específico a praça Saraiva) há muito mais de vinte ou trinta anos, mas só que, ao mesmo tempo, surgem áreas de ocupação territorial mais recente, como é o caso dos lavadores de carro (amostra C) que, segundo informações colhidas nesta pesquisa, começaram a trabalhar há menos de 15 anos nas imediações da avenida Maranhão.

Isto reflete a própria lógica do sistema capitalista, que é contraditório e cada vez mais competitivo. A existência de lavadores de carro e de vendedores ambulantes tem relação direta com a questão do desemprego, que força as pessoas que não conseguiram 
oportunidades de se estabelecer no mercado de trabalho a entrar e vivenciar o mundo do mercado informal, tendo que conviver diariamente em um espaço disputado por pedestres e lojistas e em alguns casos, por moradores de rua.

Questionados sobre o período do dia em que estes sujeitos costumam ocupar os territórios da área do objeto de estudo que estes tipos de territorialidades ocorrem durante o período do dia, em razão da grande circulação de pessoas, e também em razão de haver mais segurança no período diurno em relação ao período noturno. O resultado da coleta de dados demonstrou quase que uma unanimidade, no que diz respeito a este assunto.

No caso do período noturno, vai haver poucos comerciantes ou pedestres ocupando ou frequentando este local, com exceção da existência de alguns bares nas imediações dos locais pesquisados. Na realidade, durante a noite, observa se a existência de outros tipos de territorialidades, que, de certa forma, não são bem vistos pela população no período do dia, como, por exemplo, o consumo de drogas, a prostituição etc..

Com base na pergunta acerca de os sujeitos desta pesquisa acreditarem exercer algum tipo de identidade cultural, caracterizando a sua territorialidade no espaço ocupado, foi respondido que as pessoas que ocupam o espaço geográfico do centro de Teresina acreditam exercer a sua cultura no determinado local ocupado, e, com isso, diferenciam cada local do centro, realizando as suas determinadas territorialidades. Como afirma Santos (2001, p.19):

[...] o sentido da palavra territorialidade como sinônimo de pertencer àquilo que nos pertence... esse sentimento de exclusividade e limite ultrapassa a raça humana e prescinde da existência de Estado. Assim, essa idéia de territorialidade se estende aos próprios animais, como sinônimo de área de vivência e de reprodução. Mas territorialidade humana pressupõe também a preocupação com o destino, a construção do futuro, o que, entre os seres vivos é privilégio do homem.

Existe um sentimento em cada local ocupado, e a territorialidade é sinônimo disso, sendo então, a demarcação de identidades culturais e vai caracterizar a peculiaridade de cada local pesquisado, por exemplo, a área da avenida Maranhão onde ocorre a presença de lavadores de carro já se tornou uma área característica da cidade na qual, que as pessoas já conhecem o cotidiano daquele local, o mesmo vale para o calçadão da rua Simplício Mendes e a praça Saraiva.

Questionados sobre o tipo de influências que as determinadas formas de territorialidades causam para o centro de Teresina foi informado que existe o reconhecimento por parte de alguns sujeitos pesquisados (como é o caso dos moradores de rua e os vendedores 
ambulantes) a respeito da descaracterização do centro de Teresina em razão da presença destes determinados elementos no perímetro da rua Simplício Mendes e praça Saraiva.

Esta situação é um reflexo de um sistema econômico (o capitalista) que se desenvolve em torno das contradições sociais, gerando uma intensa concentração da renda, dividindo a sociedade em classes, e, com isso, mostrando o lado contraditório deste sistema, com o surgimento de territórios marginalizados pela presença não só de moradores de rua, de usuários de drogas, e claro, de vendedores ambulantes que, em razão da falta de trabalho se apropriam destes territórios para a prática do comércio, informal como forma de sobreviver dentro de um mundo cada vez mais competitivo. Em virtude disso, há uma influência negativa para a dinâmica do centro de Teresina, no que diz respeito à ocupação de grupos de exclusão, na sua área central.

Com base no questionamento realizado acerca das eventuais dificuldades para a ocupação de determinados territórios constata-se, existiram certos tipos de dificuldades para a ocupação de determinados territórios, principalmente por parte dos ambulantes e dos lavadores de carro em razão do grande número de trabalhadores ocupando as imediações do calçadão da rua Simplício Mendes e da avenida Maranhão, ou seja, a territorialidade se intensificou de tal forma, que fica difícil a ampliação de um tipo de ocupação territorial em certa área. Ter que caminhar pelo conhecido calçadão da rua antes citada, no Centro de Teresina, exige bastante paciência.

Não apenas pela falta de espaço (os vendedores ambulantes tomam ocupam praticamente todo o espaço), mas também pelos obstáculos que se encontram de uma ponta a outra. Também é interessante destacar a falta de manutenção do calçamento que deixa irritado tanto a quem trabalha como quem passa pelo local isso tudo se reflete nas marcas da territorialidade neste determinado local.

Questionados sobre o fato de as áreas ocupadas deixarem de ser residenciais pode-se observar que: a territorialidade no centro, (que ocorreu principalmente em caráter econômico) influenciou diretamente para o declínio das residências nesta área, sendo que, muitos dos entrevistados afirmaram que praticamente não se tem mais domicílios na área central, em razão da instalação de diversos estabelecimentos comerciais, (principalmente nas imediações do calçadão da rua Simplício Mendes e da avenida Maranhão) caracterizando o crescimento da dinâmica econômica acompanhada da derrubada de casas domiciliares. 
Em relação ao fato de se sentirem insatisfeitos, com a presença de grupos sociais e agentes econômicos ocupando os mesmos territórios, foi respondido que estes determinados tipos de territorialidades, na área central, contribuem para que os agentes formadores da ocupação territorial lutem pelos seus territórios ocupados, e também para poder garantir a sua sobrevivência dentro deles. Um bom exemplo disso refere-se, as amostras A e D (lojistas e vendedores ambulantes), onde se observa a intensa disputa para a ocupação de territórios.

No caso da área central, principalmente nas imediações do calçadão da rua Simplício Mendes, o comerciante não tolera a ocupação neste perímetro por camelôs, alegando se sentirem prejudicados do ponto de vista de suas vendas, não é a toa que estes estão comemorando a transferência dos vendedores ambulantes para o futuro shopping da cidade (localizado na praça Marechal Deodoro), além disso, os pedestres frequentemente reclamam da falta espaço para a circulação de pessoas, principalmente na rua Simplício Mendes, onde, nas imediações do calçadão, há uma intensa presença de vendedores ambulantes, atrapalhando a passagem não só de pessoas, mas também de automóveis, etc.

A respeito do fato de determinados sujeitos desta pesquisa se sentirem insatisfeito com a presença de grupos sociais excluídos obteve-se, a informação de que os grupos sociais excluídos atrapalham a vida de determinados elementos que ocupam a área central, em razão de que, estes tornam as determinadas áreas mais segregadas e também descaracterizadas, prejudicando o comércio e o fluxo de pedestres em certos locais do centro. A Prefeitura Municipal de Teresina já fez várias tentativas para a retirada dos moradores de rua nas imediações da área central, mas não conseguiu, porque o número de pessoas que pedem esmolas no centro da cidade a cada dia cresce mais. Segundo estimativas da própria prefeitura, no ano de 2008, mais da metade das pessoas que pedem esmolas tem casa para morar e ocupam os locais para conseguir ajuda financeira para poder complementar a sua renda. A insatisfação da presença de grupos sociais excluídos sempre vai existir dada a existência de um grande contingente de pessoas desempregadas além de um baixo poder aquisitivo das pessoas que trabalham.

Questionados sobre se sentiam proprietários dos locais ocupados, informaram que determinados sujeitos nesta pesquisa reconhecem que a área ocupada é pública (como é o caso dos lavadores de carro e dos moradores de rua), apesar de que certos sujeitos acreditam ser donos de alguns locais ocupados em razão da concessão por parte da prefeitura para poder exercer as determinadas atividades nos locais ocupados (como é o caso dos lojistas que 
entram em atrito constantemente com os vendedores ambulantes para estabelecer o seu predomínio econômico na área central).

Perguntados sobre os motivos para a ocupação de territórios, as respostas contidas constataram que, os territórios ocupados devem-se, em razão, principalmente, da necessidade de os atores da territorialidade estarem nos determinados locais de grande circulação de pessoas que fazem que grupos sociais e agentes econômicos atuem na ocupação das áreas que foram pesquisadas e com isso, tirando proveito desta situação.

Indagados a respeito da importância da avenida Maranhão, rua Simplício Mendes e Praça Saraiva para o funcionamento econômico da área central de Teresina as informações coletadas foram que, apesar da mudança de alguns estabelecimentos comerciais para outras áreas da cidade, o centro de Teresina ainda apresenta uma importância econômica muito grande, atraindo pessoas das mais diversas áreas da cidade. A presença da territorialidade econômica na região central é marcante, e pelo que foi observado nesta pesquisa, ainda continuará muito forte pelos próximos anos.

\section{CONCLUSÃO}

A prática do comércio por ambulantes, lavadores de carro e/ou lojistas constitui o principal elemento para a interferência de diferentes grupos sociais e econômicos na ocupação do espaço geográfico do centro, fazendo desta área, uma das mais movimentadas da cidade no que diz respeito ao fluxo de pessoas.

Estas formas de territorialidades, demonstradas neste trabalho, representam um processo resultante da própria ocupação espacial da cidade e do processo de crescimento urbano, concentrando diversos atores sociais e econômicos nesta área. Com isso, o centro apresenta territórios de ocupação territorial tradicionais, como é o caso dos lojistas que, de certa forma estão ocupando o espaço da área central há vários anos (em alguns casos há mais de quarenta anos). Apesar de que, ao mesmo tempo, surgem áreas de ocupação territorial mais recente, como é o caso dos lavadores de carros, e mesmo de vendedores ambulantes que a cada dia surgem para praticar a atividade informal no centro da cidade em virtude do aumento do desemprego.

Ficou demonstrado neste trabalho que, existe um sentimento em cada local ocupado, e que através da demarcação de identidades culturais se tem a caracterização e a peculiaridade de cada território habitado por grupos sociais ou agentes econômicos. Por exemplo, trecho da 
avenida Maranhão onde se encontra a presença de lavadores de carros (nas imediações da ponte metálica) já se tornou uma área característica da cidade onde, as pessoas já conhecem o cotidiano daquele local, o mesmo vale para o calçadão da Rua Simplício Mendes intensamente ocupada por ambulantes e lojistas e a praça Saraiva com a presença dos pedestres e moradores de rua.

Desta forma, verifica-se, que as diferentes formas de territorialidades na área central de Teresina têm como resultado as relações sociais entre indivíduos, grupo social ou agente econômicos no seu meio de referência, manifestando-se em escala geográfica local, visto que, este trabalho investigou determinadas formas de ocupação territorial no centro da cidade.

É valido ressaltar a importância e a contribuição dos lojistas, vendedores ambulantes e lavadores de carros para o desenvolvimento econômico da área central de Teresina, sujeitos estes, que possuem um significado cultural que caracterizam a identidade desta área da cidade, tendo como principal fator resultante dessas territorialidades a localização além da necessidade que esses agentes possuem para ocupar dos territórios pesquisados. Ademais, é indubitavelmente interessante afirmar que a soma destas territorialidades atrai os pedestres e, infelizmente, os moradores de rua que se aproveitam do espaço geográfico para pedir ajuda financeira as pessoas que transitam pela localidade pesquisada.

Ficam, ainda, evidentes, as diferentes formas de territorialidades, constituindo diversos mundos em um só local, visto que, a dinâmica espacial favorece para que diversos atores exerçam o seu papel dentro da área central de Teresina, como, por exemplo, quando um morador de rua pede ajuda financeira a um pedestre em frente a um estabelecimento comercial se observa três tipos de territorialidades em um só lugar.

Outros elementos a serem destacados são as intensas rivalidades e disputas territoriais para a ocupação da área pesquisada, tendo com destaque principal o confronto de ambulantes e lojistas, apresentando como resultado desse conflito, a mudança dos camelôs para outro lugar o shopping da cidade, localizado na Avenida Maranhão ao lado da Praça da Bandeira e com a inaugurado em junho de 2009. Dessa forma, a concentração dessas pessoas nessa localidade implica, provavelmente, o solapamento da territorialidade dos ambulantes na maior parte da região central.

A maior parte dos sujeitos pesquisados, afirmaram que a região se encontra intensamente ocupada e que padece de uma boa infraestrutura para a prática do comércio e a circulação de pessoas. Muitos reclamam da falta de políticas públicas no que diz respeito a 
organização das ruas, limpeza, conservação e até mesmo apoio do poder público para as pessoas que contribuem para o desenvolvimento da área central de Teresina.

Apesar disso, a maioria das pessoas entrevistadas afirma possuir uma visão positiva do centro em virtude da dinamicidade da área, da localização estratégica e a sede de alguns órgãos públicos que favorecem a uma grande circulação de pessoas. É importante mencionar também o sentimento de pertencimento e o modo de agir no âmbito dos territórios pesquisados, além das interações sociais que os caracterizam.

Muitas pessoas que ocupam territórios da região central sobrevivem através da renda que é praticado através do comércio. Desta forma, o que se observa, nesta área, é o crescimento da prática comercial, apesar de que, já alguns anos, alguns setores terem se mudado para outras áreas da cidade. Todavia, segundo os entrevistados, o centro da capital piauiense ainda é um forte atrativo, pois possui um potencial muito grande para as vendas e para os negócios.

Enfim, o que se percebeu com a realização pesquisa é que a territorialidade praticada no espaço urbano de Teresina é intensa e que a área central, representa um local estratégico para a formação dos diferentes tipos de ocupação territorial pesquisados, tais como: os lojistas, pedestres, moradores de rua, ambulantes e lavadores de carros, favorecendo para que a área mantenha a sua dinamicidade econômica contemporânea e com boas perspectivas para os anos futuros.

\section{REFERÊNCIAS}

DIAS, Genebaldo Freire. Populações marginais em ecossistemas urbanos. Brasília: IBAMA, 1994.

LIMA, Antonia Jesuíta de. Cidades brasileiras: atores, processos e gestão publica. Belo horizonte: Autêntica, 2007.

MESQUITA, Zilá Brandão; et. al. Territórios do cotidiano: uma introdução e novos olhares e experiências. Porto Alegre / Santa Cruz: UFRGS / UNISC, 1995.

RAFESTTIN, Claude. Por uma geografia do poder. São Paulo: Ática, 1993.

SOUZA, Marcelo José Lopes de. O território: sobre espaço e poder, autonomia e desenvolvimento. In: CORREA, Roberto Lobato (org.). Geografia: conceitos e temas. Rio de Janeiro: Bertrand Brasil, 1995. 
SPOSITO, M. Encarnação Beltrão. A Gestão do território e as diferentes escalas de centralidade urbana. Rio de Janeiro: URFJ, v. 3, 1998.

Recebido em Outubro de 2014

Aceito em Fevereiro de 2016

Publicado em Junho de 2016

Sociedade e Território - Natal. Vol. 28, N. 1, p. 108-121. Jan./Jun. de 2016 